\title{
Unexplained illness and deaths among injecting drug users in England: a case control study using Regional Drug Misuse Databases
}

\author{
M A Bellis, C Beynon, T Millar, J R Ashton, R Thomson, T Djuretic, A Taylor
}

North West Public

Health Observatory,

Public Health Sector,

Liverpool John Moores

University, L3 2AB,

UK

M A Bellis

C Beynon

\section{The Drug Misuse \\ Research Unit, (University of Manchester), UK \\ T Millar}

NHS Executive North West, Birchwood, UK J R Ashton

Sefton Health Authority, Sefton, UK R Thomson

Communicable

Disease Surveillance Centre, Public Health Laboratory Service,

Colindale, UK

T Djuretic

Scottish Centre for Infection and Environmental Health, Glasgow, UK A Taylor

Correspondence to: Professor Bellis (m.a.bellis@livjm.ac.uk)

Accepted for publication 13 May 2001
In April to June 2000 an outbreak of unexplained illness in injecting drug users (IDUs) in parts of the UK led to hospitalisation and usually death among those affected. ${ }^{1}$ For investigation purposes a new syndrome-based case definition was constructed as, extensive inflammation at a subcutaneous or intramuscular injection site and, either severe system toxicity or, postmortem evidence of a diffuse toxic or infectious process. ${ }^{2}$ Between 1 April and 19 June investigation of 88 hospitalised or dead IDUs with injection site soft tissue inflammation found 35 met the case definition. Despite very high mortality $(34,97 \%)$ only limited epidemiological information is available. ${ }^{1}$ However, empirical evidence identifying the characteristics of IDUs most at risk is fundamental to, better understanding the outbreak, preventing re-occurrence and developing appropriate advice should one occur in the UK or elsewhere.

By the end of June, 14 confirmed cases (12 fatal) were identified in the north west of England; the area with the majority of English cases $^{1}$ and historically a high prevalence of injecting drug users. ${ }^{3}$ Based on these cases, we present results from a case-control study that

Table 1 Cases control analyses of demographic and drug use characteristics

\begin{tabular}{|c|c|c|c|c|c|c|}
\hline \multirow[b]{2}{*}{ Factor } & \multirow[b]{2}{*}{ Cases } & \multirow[b]{2}{*}{$n$} & \multirow[b]{2}{*}{ Controls } & \multirow[b]{2}{*}{$n$} & \multicolumn{2}{|c|}{ Probability values } \\
\hline & & & & & Unmatched & $\begin{array}{l}\text { Logistic } \\
\text { regression }\end{array}$ \\
\hline \multicolumn{7}{|l|}{ At last database contact } \\
\hline Female & $50.0 \%$ & 12 & $14.2 \%$ & 120 & $<0.005$ & $<0.005$ \\
\hline Number of previous database reports (mean) & 2.7 & 12 & 2.2 & 120 & 0.426 & 0.545 \\
\hline Ever injected $\star$ & $91.7 \%$ & 12 & $85.1 \%$ & 114 & 0.536 & 0.547 \\
\hline Ever shared $\dagger$ & $77.8 \%$ & 9 & $40.0 \%$ & 60 & $<0.05$ & $<0.05$ \\
\hline Current injector & $91.7 \%$ & 12 & $62.8 \%$ & 113 & $<0.05$ & 0.069 \\
\hline Current sharer† & $20.0 \%$ & 10 & $8.2 \%$ & 49 & 0.259 & 0.337 \\
\hline Reported heroin use & $100.0 \%$ & 12 & $86.7 \%$ & 120 & 0.177 & 0.773 \\
\hline Reported injecting heroin & $90.9 \%$ & 11 & $79.8 \%$ & 94 & 0.374 & 0.388 \\
\hline Age first used heroin (mean) & 17.6 & 11 & 19.0 & 87 & 0.164 & 0.383 \\
\hline Reported cocaine use & $39.2 \%$ & 12 & $41.7 \%$ & 120 & 0.866 & 0.860 \\
\hline Reported injecting cocaine & $80.0 \%$ & 5 & $52.9 \%$ & 17 & 0.279 & 0.205 \\
\hline Age first used cocaine (mean) & 20.5 & 4 & 22.0 & 13 & 0.732 & 0.638 \\
\hline Reported methadone use & $58.3 \%$ & 12 & $69.2 \%$ & 120 & 0.442 & 0.433 \\
\hline Reported injecting methadone & $16.7 \%$ & 6 & $7.3 \%$ & 41 & 0.443 & 0.423 \\
\hline Age first used methadone (mean) & 22.8 & 6 & 22.6 & 36 & 0.745 & 0.933 \\
\hline Reported amphetamine use & $25.0 \%$ & 12 & $30.0 \%$ & 120 & 0.717 & 0.676 \\
\hline Reported injecting amphetamine & $100.0 \%$ & 2 & $50.0 \%$ & 6 & 0.206 & 0.923 \\
\hline Age first used amphetamine (mean) & 19.5 & 2 & 16.5 & 4 & N/A & N/A \\
\hline Reported benzodiazepine use & $66.7 \%$ & 12 & $47.5 \%$ & 120 & 0.205 & 0.161 \\
\hline Reported injecting benzodiazepines & $42.9 \%$ & 7 & $8.8 \%$ & 34 & $<0.05$ & $<0.05$ \\
\hline Age first used benzodiazepines (mean) & 19.7 & 7 & 20.6 & 32 & 0.726 & 0.314 \\
\hline \multicolumn{7}{|l|}{ At 1st April 2000 (mid outbreak) } \\
\hline Age (years) & 33.14 & 12 & 29.86 & 120 & $<0.05$ & $<0.05$ \\
\hline Years since first heroin use & 14.64 & 11 & 10.42 & 87 & $<0.01$ & $<0.05$ \\
\hline Years since first cocaine use & 10.89 & 4 & 7.98 & 13 & 0.07 & 0.168 \\
\hline Years since first methadone use & 8.99 & 6 & 7.19 & 36 & 0.297 & 0.336 \\
\hline Years since first amphetamine use & 12.29 & 2 & 14.82 & 4 & N/A & N/A \\
\hline Years since first benzodiazepines use & 12.18 & 7 & 9.36 & 32 & 0.085 & 0.075 \\
\hline
\end{tabular}

$\star$ One case was not reported to the drug misuse database as an injector. †Analysis of sharing is limited to injectors only. In all analyses matched controls are only included in analyses when case information is available. Comparisons of proportions injecting each substance are limited to users of those substances. Sample sizes (n) refer to number of cases and controls in each analysis. IDUs most at risk.

\section{Methods and Results}

As most cases had died, the Regional Drug Misuse Databases (RDMDs) ${ }^{45}$ were used to develop retrospective case (and control) histories on demographics and drug use. The North West RDMDs collect information on drug users combining data from diverse settings including; treatment services, police, prisons, and probation. ${ }^{45}$ Datasets do not store names but use anonymised identifiers (initials, birth date, sex, and a geographical marker). Using these, exact matches for 12 of the 14 cases were located on the databases and data from their most recent contact extracted (police surgeons $n=2$, community drug teams $n=8$, drug dependency unit $=1$, prison medical service $n=1$ ). Most $(75 \%)$ cases had been seen within the past three years. For each case 10 controls were randomly selected from individuals attending the same agency within a period of \pm six months. Identical data fields were extracted for controls and cases. All analyses were undertaken separately for each factor first without matching and then, using logistic regression provides the first empirical information on 
and including a field linking each case to their controls.

Cases were significantly more likely to be female than controls (table 1) and were more than three years older (mean age 33 on 1 April 2000). Furthermore, duration of heroin use was 4.22 years greater for cases. At last presentation to services cases were more likely to be currently injecting (that is, injected in the previous four weeks) and of all injectors, cases were more likely to have shared needles. Furthermore, among benzodiazepine users, cases had higher levels of injecting benzodiazepines, indicative of more chaotic behaviour.

\section{Comment}

Using an established multi-agency drug database we have identified demographics and drug use risk factors for the recent unexplained illness affecting IDUs in the UK. Cases were more likely (than controls) to be female. Half of cases in this study and $49 \%$ of all cases identified across the UK were female ${ }^{1}$ (compared with $30 \%$ women $\mathrm{RDMDs}^{4}$ ). Among injectors, cases also had higher levels of having shared needles and having injected benzodiazepines; indicative of more chaotic behaviour.

The most probable cause of this unexplained syndrome is Clostridium novyi infection; an anaerobic bacteria more likely to flourish in subcutaneous or intramuscular injection sites. ${ }^{1}$ Prolonged injecting drug use, especially including benzodiazepine, can lead to venous damage while injecting cocaine constricts the blood vessels. Respectively, these factors promote a greater likelihood of accidental or intended non-venous injection and reduced oxygen to blood vessels when venous injection occurs. Both factors are likely to aid growth of anaerobic bacteria. Furthermore, women have more difficulty accessing superficial veins. ${ }^{6}$

Critically, prevention and identification of further cases relies on better understanding of this condition. Extensive field studies being undertaken in Glasgow should elaborate more details of risk. In the meantime however, this study provides the first evidence of additional risk from this unexplained illness to women, older drug users and those with more chaotic injecting histories.

This report has relied on the cooperation of a wide variety of agencies including drug services, police, and prisons. We thank them for their continued commitment to a multi-agency them for their continued commitment to a multi-agency
approach to drug data. We also thank the health authorities in approach to drug data. We also thank the health authorities in
the North West Health Region for supporting this work and Jim McVeigh, Rachel Birtles and two anonymous referees for comments on the manuscript.

Funding: none.

Conflicts of interest: none.

1 Ahmed S, Gruer L, McGuigan C, et al. Update: Clostridium novyi and unexplained illness among injecting drug users2000;49:543-5.

2 Ahmed S, Gruer L, McGuigan C, et al. Unexplained illness and death among injecting drug users-Glasgow, Scotland; Dublin, Ireland and England April-June 2000. MMWR 2000; 49:489-92.

3 Department of Health Government Statistical Service. Statistics from the Regional Drug Misuse Databases for the six months ending March 1999. Statistical Bulletin 1999; 1999/ 33.

4 Donmall M, Bellis MA, Meier P, et al. Drug misuse in the Manchester and Liverpool John Moores University, 2000.

5 Hardi LV, Hounsome J, Bellis MA. Merseyside inter agency drug misuse database: annual report 1999. Liverpool: North West Public Health Observatory, 2000.

6 Derricott J, Preston A, Hunt N. The safer injecting brief. Liverpool: HIT, 1998 